\title{
O PENSAMENTO PROJETUAL COMO CAMPO RELACIONAL: TÉCNICA, COMPOSIÇÃO VISUAL E LINGUAGEM EM RELAÇÕES CONTEXTUAIS
}

\author{
Juliana Pontes Ribeiro ${ }^{1}$ \\ FUMEC \\ jpontes@fumec.br
}

Resumo: O presente artigo intenciona discutir o diálogo permanente, historicamente pontuado, entre técnica, tecnologia, metodologia e composição visual, ressaltando a importante conexão entre esses fatores na construção de linguagens que viabilizem a semântica dos projetos em Design Gráfico. Aponta questões fundamentais que constituem o debate acerca dos elementos de composição da linguagem visual no Design Gráfico e a relação semântica entre eles, tomados como resultados de procedimentos de caráter relacional diante das condições sociais e culturais de uma determinada situação de projeto. Traz ao debate a importância de uma articulação de experiências de diferentes naturezas, provenientes do entorno que forma a situação criativa, para a relação compositiva das formas tipográficas e imagéticas na linguagem gráfica de um projeto.

Palavras-chave: Design gráfico, metodologia, composição visual, estética relacional.

\begin{abstract}
This article intends to discuss the continued dialogue, punctuated historically, between technique, technology, methodology and visual composition, emphasizing the important connection between these factors in the construction of languages that allow the semantics of projects in Graphic Design. Points out key issues that constitute the debate about the composition of elements of visual language in the Graphic Design and the semantic relationship between them, taken as a result of relational character of proceedings in the face of social and cultural conditions of a given project situation. It brings to debate the importance of joint experiences of different kinds, from the environment that forms the creative situation for the compositional relation of the Typographic and imagistic forms in the graphic language of a project.
\end{abstract}

Keywords: Graphic Design, methodology, visual composition, relational aesthetics.

\footnotetext{
${ }^{1}$ Doutora em Arquitetura e Urbanismo/UFMG; Mestre em Comunicação Social/UFMG; Graduada em Belas Artes/UFMG; jpontes@fumec.br
} 


\section{INTRODUÇÃO}

A intenção desse artigo foi tocar em alguns pontos fundamentais do Design Gráfico como atividade e como campo de conhecimento, para demonstrar justamente a sua complexidade enquanto um domínio formado historicamente por uma combinação interdisciplinar de saberes técnicos e teóricos. Essa natureza híbrida coloca o campo do Design Gráfico em uma posição de constante atualização também devido à sua capacidade de absorver mudanças tecnológicas e gerar recursos metodológicos para atender às suas demandas. Enquanto área profissional, o Design Gráfico também se modifica para dar respostas à problemática dos projetos em cada época e para realizar-se como um campo de agenciamento da cultura e do universo simbólico compartilhado socialmente. Tudo isso realizado através de um agenciamento criativo entre componentes textuais e imagéticos, uma lógica de composição que relaciona conceitualmente elementos visuais.

Visto dessa forma, o Design Gráfico ganha complexidade ao ultrapassar a técnica e a capacidade de representação para envolver outras habilidades que antecedem a sua ação direta de materialização visual de uma forma gráfica. A ideia de concepção de uma peça gráfica, em relação à sua forma física e também à sua função, coloca novas demandas em jogo, pois conceber um produto traz em si tanto a idealização, que é movida por uma intenção de uso e um propósito estético, como a necessidade de se pensar meios de materialização dessa ideia, ou seja, um pensamento projetual. A atividade exige, portanto, a importante tarefa de elaboração de um projeto, ou seja, além de ser um desenhista, esse profissional deve conseguir estabelecer metas e planejar suas ações em direção à realização das mesmas. A matriz metodológica e a origem interdisciplinar do Design como campo de conhecimento ganham forma a partir de requisitos básicos: intenção (propósito de comunicação); projeto (planejamento em diálogo com o campo da arquitetura); e desenho (execução de atividades de representação ligadas ao campo das artes plásticas).

Além dessas questões, o campo do Design sugere outras reflexões. Vilém Flusser, filósofo que destinou vários de seus textos para o tema, destaca, entre os significados ligados ao termo 'design', as expressões "esquema maligno" e "conspiração", associados à ideia de estratégia, planejamento e projeto. Nesse sentido o autor associa o entendimento da palavra a um contexto de "astúcias e fraudes", ou seja, o designer cria "dispositivos de enganação" por serem artifícios - da ordem do que é artificial - construídos para driblar dificuldades naturais do homem, realizando tarefas que nós não conseguimos e nem encontramos de maneira tão eficiente no mundo natural. Um exemplo disso está em uma caneta: os corantes e hastes para auxiliar na pintura feita à mão estão na natureza, mas as variações de bicos, ponteiras, cores, espessuras do traço, funções, etc., são artificialidades feitas pelo designer para enganar as limitações da natureza. (FLUSSER In: CARDOSO, 2007).

Visto dessa forma, o Design é uma atividade responsável por criar uma trama, no sentido de uma articulação intelectual, para conseguir realizar seus objetivos funcionais de uma maneira ainda não encontrada no meio natural e, junto a isso, tem a astúcia de desenvolver um dispositivo prático que possui um aspecto estético encantador, a ponto de simular também o poder de sedução das formas naturais. Essa sedução, em grande parte, usa artifícios que fazem referência às formas criadas no campo da cultura, construindo um discurso visual pautado em um resultado híbrido, que recorre aos modelos culturais e aos modelos naturais ao mesmo tempo. O Der 
tem a natureza como inspiração e a cultura como referência. Essa conexão é que permite a "astúcia" do Design, pois a forma facilita a função técnica e seduz o olhar pela beleza e novidade. Entendendo o Design dessa maneira, forma e função não se pautam somente por uma relação de subordinação, como na tradição funcionalista, na qual a forma deveria facilitar a função prioritariamente. A inovação nas formas do Design é vista, nessa abordagem, como um recurso metodológico que determina sua potência como produto da cultura e sua competência para instaurar novas relações entre os usuários e os objetos, que podem ser de caráter objetivo ou subjetivo, inserindo a possibilidade de transformação das atividades do cotidiano tanto por sua função como por sua forma.

Flusser (In: CARDOSO, 2007) lembra que o termo design aproxima arte e técnica, conexão esquecida por um longo período de tempo após o Renascimento, época em que os grandes gênios, como Leonardo Da Vinci, usufruíam de um pensamento interdisciplinar enquanto criavam suas obras, que se voltavam para inúmeros fins. Retomando esse momento histórico e seus grandes mestres, o autor italiano Franceso Morace (2009) afirma que estamos vivendo um novo Renascimento, em direção a uma produção de bens de consumo de caráter mais cultural do que tecnológico. Essa constatação reforça a vocação do Design para acionar, simultaneamente, aspectos subjetivos e objetivos na relação entre o homem e os objetos. Para Morace esse momento retoma alguns aspectos essenciais para o Design: a percepção, recolocando em cena o corpo e os seus sentidos; a memória, que busca em referências passadas imagens carregadas de significado social; a criatividade aplicada aos espaços compartilhados; a emoção pela carga afetiva e a beleza pela plasticidade das formas.

\section{DESENVOLVIMENTO}

\subsection{Tecnologia e linguagem: encontros criativos na relação compositiva de um layout}

A imagem, antes do alfabeto e da escrita fonética, sempre cumpriu diversas funções sociais como a de ser um registro de ideias, uma forma de narração histórica e um instrumento de dominação das forças da natureza. Nas cavernas as cenas da vida, os animais caçados e os eventos naturais eram capturados em imagem e fixados nas pedras como representação de um poder mágico e como forma de organização social. A religião, as relações interpessoais, a garantia da sobrevivência, a defesa da comunidade, o prazer e todas demais esferas da vida estavam entrelaçadas na rotina do grupo, manifestando-se também nas pinturas e objetos. Nesse momento a representação imagética desses temas era um dado cultural que fazia parte da rotina das comunidades. A consciência do valor instrumental dos sinais gráficos (elementos visuais de caráter abstrato que condensam significados a eles atribuídos arbitrariamente) e a racionalização do seu uso se deu aos poucos, à medida que o homem percebia que os mesmos comportavam simultaneamente diversas finalidades ou interpretações e poderiam ser reconhecidos coletivamente.

Esse uso racional e planejado das inscrições gráficas sempre apresentou a dimensão técnica e a dimensão estética como instâncias inseparáveis, em uma conexão na qual o primeiro condicionava o segundo através de suas possibilidades e limitações. No processo de consolidação de um pensamento metodológico próprio, o Design Gráfico sempre alinhou suas revoluções estéticas e de linguagem às 
transformações técnicas e tecnológicas alcançadas em sua história. Traços à mão, xilogravura, fotografia, offset e tecnologia digital foram alguns dos recursos que renovaram o fazer na área, proporcionando novos modos de ação criativa e determinando mudanças nos métodos e metodologias.

A cada época as formas de representação do mundo mudam e o homem utiliza algum tipo diferente de técnica para a criação e registro das imagens gráficas geradas. Quando, por exemplo, os sumérios gravavam em placas de argila sua escrita ideográfica, eles moldavam os seus sinais gráficos e figuras de acordo com os recursos técnicos de representação disponíveis. A escrita cuneiforme dos sumérios tem seu traço muito condicionado pela resistência dos materiais de suporte e instrumentos de gravação, o que lhe confere a forma de cunha resultante dos caniços talhados obliquamente em um dos lados e empunhados por um pilão para perfurar o suporte (MARTINS, 1998). Da mesma forma os chineses, quando gravavam seus ideogramas em cascos de tartaruga, seda ou bronze utilizando o pincel de bambu, geravam formas claramente determinadas pela maior ou menor resistência do suporte ao material de inscrição e pelo grau de absorção da tinta. Igualmente, os egípcios tinham a delicadeza e fragilidade dos rolos de papiro como desafio de impressão para os seus hieróglifos e fator condicionante para as formas de suas vinhetas e grafismos.

Com a escrita fonética e o alfabeto também não foi diferente, pois o estilo do desenho das primeiras letras foi resultante das inscrições em pedras deram origem à vários estilos tipográficos ainda usados hoje, com suas linhas retas e limpas. Na Idade Média a escrita à mão, junto com as iluminuras e miniaturas que ornavam as páginas do códices, eram um conjunto coeso, esteticamente unificado em seu estilo, ambos decorrentes do uso da técnica manual à base de tinta e ouro para a inscrição de textos e imagens. Com o processo de mecanização da impressão de textos através da prensa de Gutemberg, que tem na Bíblia de 1455 a sua primeira grande referência de qualidade técnica, alguns formatos dos tipos móveis em chumbo foram baseados nos desenhos das letras medievais. A mecanização democratizou o acesso aos impressos pela quantidade e velocidade da impressão, mas durante muito tempo ainda se mostrava como uma técnica pouco flexível em seu resultado estético. Essa limitação se deve ao fato de que a impressão mecanizada ficou atrelada aos padrões de referência dos livros manuscritos por alguns séculos pois, de acordo com Martins (1998), os primeiros impressos imitaram a composição de página, margens, mancha de texto, iluminuras, miniaturas e o desenho das letras dos códices.

Percebe-se, então, uma estética predominante em decorrência de uma limitação tecnológica. Com essa técnica de impressão consolida-se, assim, a separação entre texto e imagem por causa das suas restrições: o texto era gravado pela composição em tipos móveis de chumbo e as imagens eram feitas por xilogravura. As ilustrações tendem a se simplificar em função da adequação à técnica de gravação em xilogravura, técnica que demanda um traço mais rígido, com menos nuances de detalhes e poucos traços gestuais. Ganha-se em agilidade, volume e reprodução dos impressos, mas perde-se em personalidade, diferenciação de estilo e sensibilidade estética. Essa separação entre as tecnologias de impressão do texto e da imagem fazem com que cada um desses conteúdos fiquem restritos às possibilidades e à plasticidade que as suas respectivas técnicas permitem, o que isola conceitualmente esses dois universos pois eles passam a responder a diferentes parâmetros de criação em um mesmo espaço gráfico. 
Somente no século XIX, em sintonia com os movimentos Arts and Crafts de Willian Morris, na Inglaterra, e Art Noveau, na França, surge uma série de produtos gráficos e artísticos que colocam em questão a padronização estética resultante do processos industrial, recuperando o fazer manual e as variações provenientes das formas orgânicas e do traço gestual. Essas mudanças também foram impulsionadas por uma nova técnica de impressão - a litografia - que foi utilizada intensamente nesse período e permitiu essa flexibilidade estética, pois as imagens e textos eram desenhados à mão diretamente na matriz de pedra. Os pôsteres artísticos feitos nessa nova técnica permitiam o gesto inclusive na grafia dos textos recuperando, dessa maneira, a união entre texto e imagem em termos de linguagem, pois torna-se possível novamente aproximar plasticamente o estilo do traço usado nas figuras e o estilo do traço usado nas letras.

A litografia aliada a outra técnica de reprodução seriada, no caso a fotografia, que também surge nessa mesma época, reúne a separação de cores (policromia) da primeira com a reprodução da imagem em filme (fotolito) para gravação na chapa de impressão da segunda e dá origem ao processo de impressão em offset. Essa tecnologia de impressão ampliou a gama de possibilidades de aplicações de imagens de todos os tipos (fotografias, desenhos, pinturas, etc.) associadas à uma variação maior de tipografias também. Richard Hollis (2001) chega a afirmar que a litografia permitiu um controle de cores, composição de tipos e impressão que pode ser considerado como o início do Design. Mais à frente, a técnica de impressão offset aliada, nos anos 1980, ao surgimento das tecnologias digitais de criação, consolidou a reaproximação entre texto e imagem em termos de linguagem durante o processo criativo do layout digital e também nos recursos de impressão. Recupera-se, a partir de então, a condição de se criar um projeto em Design Gráfico tendo como parâmetro um mesmo conceito plástico para a mancha tipográfica assim como para os elementos iconográficos, compartilhando as mesmas referências estéticas e unificando graficamente o resultado.

Por fim, hoje temos tanto a etapa de criação quanto o processo de impressão feitos através de recursos digitais, o que pode se verificado tanto nas áreas que geram produtos impressos como nas áreas que tratam especificamente de projetos dinâmicos ou virtuais, como animações, Motion Design, Web Design e outras que também sofrem influências desses novos recursos tecnológicos à disposição. Vale ressaltar que essa influência distancia-se da imposição de padrões e estilos que era própria das limitações tecnológicas de tempos passados, pois cada vez mais novas possibilidades criativas são oferecidas por esses recursos. Quanto mais avançadas são as tecnologias, maior é a amplitude de ferramentas criativas que elas oferecem e, a princípio, a padronização estética e a uniformização de linguagem deveriam ser reduzidas. Porém, muitas vezes o pouco domínio e o raso conhecimento sobre essas tecnologias e seus usos, somado também a processos criativos pouco planejados e sem pesquisa, conduzem os projetos à soluções repetitivas, que somente reproduzem os padrões mais utilizados no mercado de uma forma desconectada das reais necessidades de inovação ligadas às demandas do projeto e à natureza desse campo de conhecimento. A inovação tecnológica deve ser, sim, uma força motriz para impulsionar os ganhos estéticos e as revoluções de linguagem possíveis na área e nunca um recurso engessado de mecanização do ato criativo. 


\subsection{Elementos de linguagem e estruturas ordenadoras das formas}

O Design Gráfico fundamenta-se na criação e combinação de três categorias de elementos visuais: os gráficos (formas abstratas e geométricas, cores, linhas, pontos, grafismos diversos); os tipográficos (letras, numerais e outros caracteres da escrita) e os iconográficos (elementos imagéticos e figurativos) para a organização do que se denomina espaço gráfico, que é a área na qual serão dispostos os elementos de um layout. O espaço gráfico pode ser o tradicional livro e os demais impressos, como cartazes e materiais promocionais, ou as telas virtuais, nas quais o designer vai lidar com a dinâmica, o movimento e a interação. Objetos tridimensionais também servem como espaços de aplicação das composições gráficas, como por exemplo embalagens e superfícies de objetos, roupas, acessórios, ambientes e edificações. Os elementos que compõem visualmente esse espaço gráfico podem se organizar em formas como pictogramas, logotipos, símbolos de marcas, ilustrações, sinalizações, fotografias, blocos de textos e outros. Além disso, o Design Gráfico dialoga hoje com áreas afins, como o Design Sonoro, que tem uma autonomia criativa no que diz respeito à produção de vinhetas e assinaturas sonoras, mas também contribui para áreas de produção de imagens em movimento, como vídeo, animação e interfaces eletrônicas.

A abordagem do espaço gráfico como área livre para receber inscrições e representações de natureza visual, ou seja, para a combinação das categorias de elementos citadas acima, por várias vezes esteve atrelada a algum sistema organizador. Um exemplo é a seção áurea ${ }^{2}$, utilizada em universos de aplicação variados como na arquitetura de edificações gregas (por exemplo o Parthenon), em pinturas renascentistas, na análise do alfabeto no séc. XV por Albrecht Durer e até mesmo na tentativa de explicar a música de Béla Bartók (HURLBURT, 1999). Essa necessidade de ordenar o espaço está em sintonia com a necessidade de organização do mundo e das relações sociais que nele se estabelecem. Desde as sociedades mais antigas, existe uma busca constante por uma estrutura que assegure a ordem, a previsibilidade e o controle, demonstrando ser esse um traço característico da busca pela civilização. Samara (2007, p. 9) já aponta uma relação entre essa necessidade histórica e o pensamento estrutural: "Os chineses, os japoneses, os gregos e romanos, os incas - todos esses povos seguiam ideias estruturais ao construir cidades, fazer guerras e organizar imagens".

Inspirado por essa tendência a uma lógica ordenadora do mundo e impulsionado pela padronização das sociedades industriais, surge um sistema organizador para o layout conhecido como grid, que foi reafirmado no Design modernista. $\mathrm{Na}$ vertente histórica do design conhecida como Estilo Internacional, original da Suíça, essa estrutura ganha a denominação de grid tipográfico, e é definida como "um sistema de planejamento ortogonal que divide a informação em partes manuseáveis" (SAMARA, 2007, p. 9), tornando-se oficialmente fundamental para o arcabouço teórico do Design. O grid ou grade é uma estrutura organizadora do espaço gráfico, que serve como referência para a distribuição dos elementos verbais e dos elementos não-verbais no mesmo. O grid funcionou por muito tempo como um método projetual, pois consistia em uma etapa fundamental para o início de qualquer

\footnotetext{
${ }^{2}$ Seção áurea é um "princípio de proporção baseado na divisão de uma linha em duas partes, uma maior e outra menor"(HURLBURT, 1999, p. 51), que vai gerar um retângulo áureo a partir de uma série de projeções de triângulos e curvas matematicamente determinados em relação às medidas da linha inicial.
} 
ação projetiva no Design Gráfico. Como já foi visto anteriormente, os manuscritos medievais instauraram uma lógica de composição da mancha de texto e de sua relação com as iluminuras e miniaturas que perdurou ao longo das mudanças para a impressão mecanizada e foi padronizada por esta última até o século XIX. Diferente disso, a ideia do grid não passa por uma padronização dos resultados perceptíveis das composições visuais da página impressa, mas por uma uniformização da metodologia projetual no que se refere à lógica de abordagem criativa do espaço gráfico disponível. O grid é, portanto, uma estrutura subjacente à composição visual, que conduz o processo de criação mas nem sempre é perceptível no resultado final.

A partir da década de 1970 a rejeição ao grid como estrutura fundamental e forma de controle necessária ao processo criativo foi aumentando, acompanhando as mudanças que caracterizam o período e fazem parte do pensamento pós-moderno. 0 Design pós-moderno, que na verdade representa mais uma condição cultural de produção do que uma característica estilística (POYNOR, 2003), surge em sintonia com a diluição dos limites e fronteiras na sociedade, onde as relações entre trabalho, família e instituições ficam mais fluidas e dinâmicas, respondendo a formatos mais abertos e menos convencionais. Essas transformações significaram uma mudança de paradigma para o Design, pois a ideia de desconstrução passou ocupar o lugar central nos debates e conceitos criativos, em oposição ao pensamento estruturador equivalente a uma lógica de ordenação e construção. Como reflexo disso, a experimentação gráfica e a exploração de novas linguagens para o Design recuperaram recursos provenientes do campo das artes plásticas assim como de outra áreas criativas como método projetual, o que levou a uma opção por projetos mais conceituais e subjetivos do que funcionais e objetivos. Esse deslocamento de postura levou muitos designers a desafiarem as regras clássicas de legibilidade e estruturação de layout, abandonando ou subvertendo a noção de grid e o seu uso.

A necessidade de retomada da ideia de estrutura no Design Gráfico aparece com as demandas de interfaces para o mundo digital, que articulam diversos links e conexões de informações pensadas de acordo com um wireframe (distribuição dos conteúdos em um sítio) e uma arquitetura da informação (maneira como esses conteúdos se relacionam). Mais uma vez fica evidente que novas tecnologias impõem mudanças metodológicas e de linguagem para o Design e que, muitas vezes, são baseadas em conceitos já existentes que são revisitados de acordo com novas situações de projeto. O Design para o universo interativo do mundo digital mantém um relação próxima com o pensamento estruturador do grid mas traz em si algo novo que é a possibilidade de navegação por essa estrutura. Inclusive, a ordenação dos sistemas interativos e em rede caracteriza-se como uma metodologia, que busca a hierarquização e sistematização da informação, disponibilizando vários meios e caminhos de acesso que trazem a personalização da navegação pelo usuário. Enquanto no impresso o grid estruturava uma forma final definitiva de apresentação dos conteúdos de um projeto, no universo digital o grid serve para estruturar um grande número de possibilidades de apresentação e também de ordenação do que pode ser visto.

\subsection{A composição dos elementos visuais como pensamento relacional no Design.}

Independente do uso ou não de estruturas ordenadoras dos elementos visuais, o exercício de linguagem no Design Gráfico se pauta fortemente na composição desses 
elementos no espaço. A noção de composição implica a distribuição das relações de forças estabelecidas entre os elementos visuais, promovendo uma orquestração do conjunto de intervenções no espaço gráfico. Rudolf Arnheim atribui a essas forças a capacidade de proporcionar experiências sensoriais através das " [...] interações entre as partes e o todo." (ARNHEIM, 2011, p.10). O que se consegue com esse jogo de relações visuais é atuar na percepção da imagem gráfica, associando aspectos sensoriais às mensagens lidas nos textos e nos elementos iconográficos. Em uma analogia à ideia de jogo pode-se comparar o grid, que se configura como uma estrutura subjacente ao layout, a um tabuleiro e a composição compara-se ao conjunto de regras para a movimentação das peças, que são os elementos visuais. A palavra "regras" é entendida nesse contexto como uma variedade de princípios para realizar as combinações e efeitos entre os elementos visuais e o espaço gráfico, e não como um roteiro pré-definido para a organização final do layout. O conhecimento das regras promove a jogabilidade ${ }^{3}$, pois torna o jogador apto a criar percursos estratégicos próprios e legítimos para os seus objetivos dentro do jogo. Essa noção está diretamente relacionada com a consciência dos efeitos que podem ser gerados no uso das várias combinações possíveis entre as informações visuais acionadas no ato de criação. Se o conhecimento das "regras" do jogo, ou seja, dos princípios que levam a esses efeitos específicos aponta para uma possibilidade de uso planejado desses recursos, estamos falando de uma lógica operacional, de uma metodologia. Uma metodologia que tem como princípio estabelecer relações.

Uma outra comparação é apresentada por Donis A. Dondis (2000), que estabelece similaridades entre o processo de composição dos elementos visuais e a lógica de construção da sintaxe na linguística. A sintaxe é o conjunto de regras que regem a escrita e a organização dos elementos textuais na estrutura de frase que conhecemos. Da mesma forma, a composição gráfica é um conjunto de recursos que podem auxiliar o processo criativo a alcançar suas metas enquanto mensagens visuais, sejam elas de caráter subjetivo ou objetivo. No caso de uma frase dentro da composição linguística de um texto, a utilização da sintaxe é feita para a ordenação dos elementos formadores de sentido em busca de um entendimento comum acerca desse conteúdo, realizado a partir do compartilhamento de regras capazes de sistematizar uma língua. No caso da linguística, o leitor tem que passar por algum aprendizado formal sobre essas regras justamente para conseguir decodificar esse sistema de comunicação. Porém, frente a uma composição visual temos o que Donis A. Dondis (2000) chama de "alfabetismo visual", que é um processo de aprendizado informal, desenvolvido por meio de uma capacidade perceptiva do sujeito acerca das formas em relação ao contexto no qual estão inseridas considerando, para tanto, o seu repertório cultural e a sua memória afetiva. A compreensão das mensagens visuais se desenvolve com o tempo e a experiência de contato com esses conteúdos sendo, portanto, um processo associativo, de caráter relacional, capaz de acionar recursos de naturezas distintas - sociais, culturais e pessoais - em função da atribuição de um sentido para a mensagem. Diferente do código linguístico, a sintaxe visual não forma palavras com significados pontuais e estritos, mas aciona referências mais amplas que

\footnotetext{
${ }^{3} \mathrm{O}$ termo jogabilidade é originalmente usado para os jogos em ambientes eletrônicos e indica entre outras coisas a habilidade para o jogo. Nas palavras de Guilherme Xavier: "[...] habilidade ad hoc do jogador para com os mecanismos do jogo [...]" (XAVIER In: COELHO et al. 2008, p. 201)
} 
são contextualizadas pelo observador de acordo com as suas experiências individuais e coletivas.

Autor do início do séc. XX e referência sobre o assunto, o artista plástico Kandinsky (1997), ao tratar dos elementos visuais fundamentais - o ponto, a linha e o plano - e suas relações de forças, aponta que essas estruturas estão presentes em todas as artes, citando como exemplo os ângulos, linhas estruturais e pontos de intercessão da arquitetura; os passos nas pontas dos pés que conectam-se em linhas imaginárias na dança; as notas e pautas musicais; além das formas da pintura e do desenho, até as estruturas da engenharia. Também em todas as áreas do Design (Gráfico, Produto, Interiores e Moda), a noção de percepção das formas gráficas a partir de suas relações de composição visual no espaço surge como pensamento subjacente à criação, demonstrando, assim, ser uma lógica transdisciplinar. Contraste, harmonia, equilíbrio, desequilíbrio, simetria, assimetria, tensão, ritmo, escala, proporção, luz e sombra são algumas das relações que se fazem constantes no pensamento metodológico do Design enquanto exercício de linguagem em direção a uma concepção ampla de um espaço de criação, no qual o princípio norteador baseiase na articulação de formas e cores em relações de sentido. Aponta-se para a ideia de que o pensamento relacional modela o processo criativo em Design, caracterizando-se como uma metodologia em comum. Encontra-se aqui um fundamento transdisciplinar que perpassa os campos do Design e de qualquer atividade que envolva a percepção espacial e visual: o pensamento relacional como agenciador do exercício de linguagem.

Sendo a composição dos elementos visuais em um espaço determinado um recurso formador da linguagem em várias artes, cabe buscar reflexões teóricas dos campos dessa natureza para ampliar o pensamento aqui proposto. No caso, a teoria da estética relacional, descrita por Nicolas Bourriaud (2009) ao tratar da arte contemporânea, será o parâmetro escolhido para estimular esse debate justamente por tratar da necessidade de se articular relações durante o processo criativo. $\mathrm{O}$ autor associa esse pensamento a uma teoria da forma, mas afasta-se da estética formalista ao tratar a forma como um fator que vai além do seu aspecto material e alcança sua definição a partir de uma "propriedade relacional" acionada pelo olhar do sujeito observador. Nesse sentido a forma não existe recortada em si mesma, mas passa a existir por sua relação com outras formas e com o contexto. Há nessa abordagem um pensamento novo em relação à noção de forma e de suas relações de composição no espaço, que não se limitam mais somente ao jogo de forças visuais como equilíbrio, contraste, proporção, escala e outras de mesma natureza. A capacidade relacional que está em jogo não é só visual, mas compreende-se como a possibilidade de estabelecer um diálogo com o ambiente social e cultural no qual está inserida a forma observada e o seu observador.

Ao tratar da percepção as formas, Donis A. Dondis (2000) comenta que as nossas diferentes maneiras de reagir às imagens dependem de alguns fatores, entre eles do nosso estado psicológico, do ambiente no qual essas imagens estão inseridas e dos nossos condicionamentos culturais. Esses elementos atuam como condicionantes para o olhar e possuem a capacidade de alterar a compreensão das imagens de acordo com cada situação e com cada observador. Esse modo de compreender a relação entre imagem, sujeito e entorno ainda difere da noção de "propriedade relacional" citada por Bourriaud (2009). Quando afirma-se que o contexto psíquico e social oferece limites e condicionamentos para o entendimento das imagens percebe-se esses 
fatores como dados externos à criação visual, que vão interferir na relação entre observador e objeto observado em um momento posterior à elaboração da imagem. Já a estética relacional traz um parâmetro diferente: a imagem construída inclui o contexto como parte integrante da obra, em suas formas e em seu conteúdo. Nesse ponto a arte contemporânea, por exemplo, se apropria dos espaços públicos, dos fluxos de pessoas e automóveis nos espaços urbanos, das edificações e da paisagem para gerar com esses elementos, que são visuais e conceituais, suas composições. Assim, o contexto é a obra e vice-versa. Portanto o que seria tratado como um limite externo passa a ser incorporado como um dado interno da criação.

Se o Design Gráfico, assim como as demais áreas de atuação do Design, surgiram e se desenvolveram em intensa afinidade com outros campos, especialmente com as artes, podemos pensar algum tipo de aproximação entre o conceito citado e a noção de composição dos elementos visuais no Design contemporâneo? Para fazer essa aproximação, podemos partir da observação da arte urbana e do seu diálogo com o mobiliário coletivo, edificações e muros, sendo estes espaços já existentes na cidade e apropriados por esses artistas como suporte, estrutura e elementos de composição das suas imagens. A um passo da arte e do Design, a arte de rua só existe para e com o espaço urbano, ou seja, só existe em função das relações que ela percebe e materializa com o contexto.

Já os produtos de Design contemporâneo apresenta na atualidade algumas vertentes que demonstram também uma certa incorporação desse pensamento relacional frente ao contexto de projeto. No Design Editorial, por exemplo, temos a forte influência da estética dos livros-objeto, formato original da arte, que traz para o Design a possibilidade de incluir na estrutura formal do livro a ideia de um objeto pertencente ao universo contextual da obra. Esse tipo de recurso materializa a presença de elementos do contexto no raciocínio criativo do Design. Outro exemplo está nas embalagens multifuncionais, que vão além de sua relação estreita de forma e função com os conteúdos que ela embala para se transformarem em objetos ou mesmo mobiliários autônomos, relacionados com o contexto social do usuário e não mais com o produto embalado. O Design de superfície também deve ser ser citado como exemplo pois integra o ambiente simbólico de um projeto ao contexto social, cultural e visual do usuário, construindo essas relações durante a atividade de concepção da peça. Vários outros exemplos podem ser lembrados aqui, porém o que importa é verificar a presença dessa lógica em comum entre o Design e a arte hoje, demonstrando que essas e outras áreas afins trazem para si mudanças pertinentes ao seu tempo no processo criativo. O entendimento do recurso de composição dos elementos visuais no espaço é uma estratégia que se atualiza a cada momento histórico ou social, renovando a maneira como articula o jogo de forças visuais entre a criação e o contexto do projeto.

\section{CONCLUSÃO}

Todos esses pensamentos apontam para uma demanda por estudos acerca da complexidade da linguagem visual enquanto campo relacional do Design Gráfico e para a potência semântica dos arranjos daí resultantes. O potencial interdisciplinar dessa área garante a sua permeabilidade aos saberes de campos afins, qualidade e desafio que não deve ser abandonado ou negligenciado nas abordagens críticas sobre o fazer e o pensar acerca do Design Gráfico. O que foi discutido nesse artigo, portanto, 
trata-se de aspectos da composição estrutural que fornece a sustentação do campo enquanto território produtor de conhecimentos, métodos e tecnologias específicas em função de articulações de linguagem em diferentes épocas e situações culturais.

O Design Gráfico, enfim, traz em si essas reflexões, conectando-se com a cultura e com o contexto social através de representações gráficas que simbolizam, sinalizam, identificam e atribuem sentido ao mundo e seus objetos por meio de relações entre elementos de natureza visual. Nasce mesclando arte, sensibilidade, vocação comunicacional, objetividade projetual e um método próprio que une cultura e técnica como recursos criativos. Palavra e imagem como conteúdo, linguagem e instrumento de criação, aliados a um pensamento inovador, compõem os desafios do Design Gráfico como processo metodológico, área profissional e campo de conhecimento.

\section{REFERÊNCIAS}

ADG. $O$ valor do design: guia ADG Brasil de prática profissional do designer gráfico. São Paulo: Editora SENAC; São Paulo: ADG Brasil Associação dos Designers Gráficos, 2003.

ARNHEIM, Rudolf. Arte e percepção visual: uma psicologia da visão criadora. São Paulo: Cengage Learning, 2011.

BOURRIAUD, Nicolas. Estética relacional. Tradução Denise Bottmann. São

Paulo: Martins Fontes, 2009.

COELHO, Luiz Antonio L.; FARBIARZ, Alexandre; FARBIARZ, Jackeline Lima (orgs.). Os lugares do design na leitura. Rio de Janeiro: Editora Novas Ideias, 2008.

DONDIS, Donis A. A sintaxe da linguagem visual. São Paulo: Martins Fontes, 1997.

GARRETT, Jesse James. The elements of user experience: user-centered design for the web. Indianapolis: New Riders, 2002.

HOLLIS, Richard. Design gráfico: uma história concisa. São Paulo: Martins Fontes, 2000. HURLBURT, Allen. Layout: o design da página impressa. São Paulo: Nobel, 1999.

ICOGRADA. Disponível em <http://www.icograda.org> Acessado em 2012.

KANDINSKY, Vassily. Ponto e linha sobre plano. São Paulo: Martins Fontes, 2001.

LEVY, Pierre. As tecnologias da inteligência: o futuro do pensamento na era da informática. Rio de Janeiro: Ed. 34, 1993.

LUPTON, Ellen. Novos fundamentos do design. São Paulo: Cosac Naify, 2008.

MARTINS, Wilson. A palavra escrita: história do livro, da imprensa e da biblioteca. São Paulo: Editora Ática, 1998.

MEGS, Philip B.; PURVIS, Alston W.. História do design gráfico. São Paulo: Cosac Naify, 2009.

MICHAELIS: dicionário prático inglês. São Paulo: Editora Melhoramentos, 2009.

MORACE, Francesco. Consumo autoral: as gerações como empresas criativas. São Paulo: Estação das Letras e Cores Editora, 2009. 
MUNARI, Bruno. Design e comunicação visual: contribuição para uma metodologia didática. São Paulo: Martins Fontes, 1997.

POYNOR, Rick. No más normas: diseño gráfico posmoderno. México: Ediciones G. Gili, SA de CV, 2002.

SAMARA, Timothy. Grid: construção e desconstrução. São Paulo: Cosac Naify, 2007.

STOLARSKI, André. Alexandre Wollner e a formação do design moderno no Brasil:

depoimentos sobre o design visual brasileiro. São Paulo: Cosac Naify, 2005.

VILLAS-BOAS, André. 0 que é [ e o que nunca foi ] Design Gráfico. Rio de Janeiro: 2AB, 2000.

. Utopia e disciplina. Rio de Janeiro: 2AB, 1998. 